\title{
ENERGIA SOLAR: METODOLOGIA PARA AVALIAÇÃO DO LOCAL DE INSTALAÇÃO DE SISTEMA FOTOVOLTAICO FOMENTANDO A EDUCAÇÃO AMBIENTAL
}

Claudemiro Lima Júnior ${ }^{1}$

Bruno Basílio Rodrigues ${ }^{2}$

Fabrícyo Villa Verde Silva ${ }^{3}$

Leudiane Rodrigues Luz ${ }^{4}$

Regina Lúcia Félix de Aguiar Lima ${ }^{5}$

Resumo: O estudo da energia solar, como forma de promover Educação Ambiental, deve orientar o uso de recursos naturais para promover práticas sustentáveis por meio de reflexões, discussões e experiências, objetivando o desenvolvimento de habilidades e modificando atitudes em relação ao meio ambiente. Este trabalho teve como objetivo apresentar um estudo sobre a localização de um sistema fotovoltaico realizado por um grupo de alunos, abordando os conceitos de energia solar e sustentabilidade. Consiste de uma metodologia para a avaliação do local de instalação do sistema fotovoltaico e sugestões para a utilização dos conceitos de energia solar e sustentabilidade fomentando a Educação Ambiental em sala de aula.

Palavras-chave: Energia Renovável; Ensino de Física; Interdisciplinaridade.

\footnotetext{
1Universidade de Pernambuco - E-mail: claudemiro.lima@upe.br

2 Instituto Federal Sertão Pernambucano - E-mail: brunobasilior@gmail.com.

3 Instituto Federal Sertão Pernambucano - E-mail: fabricyo.villa@gmail.com

4Universidade de Pernambuco - E-mail: leudianeluz@gmail.com

5Universidade de Pernambuco - E-mail: regina.aguiar@upe.br
} 


\section{Introdução}

O desenvolvimento econômico de um país implica em crescimento da demanda energética e traz consigo questões relativas à preservação ambiental (BRASIL, 2014). No Brasil, a matriz elétrica é predominantemente proveniente de usinas hidrelétricas, que segundo dados do Operador Nacional do Sistema Elétrico (ONS), geram cerca de 70\% da energia elétrica (EIFLER NETO, 2012, p.16). Essa fonte de energia, apesar de renovável, traz impactos ambientais e a geração de energia pode ser afetada por fenômenos relacionados aos regimes pluviais, como as secas. Em períodos de secas prolongadas, o atendimento à demanda de geração energia, sem provocar grandes mudanças na utilização do abastecimento de água para a população e para a atividade agrícola, são utilizadas termelétricas. Estas, além de fornecer eletricidade com custo mais elevado, contribuem para a emissão de gases causadores do efeito estufa, principais responsáveis pelo aquecimento global e impactos ambientais associados ao fenômeno (LIMA JUNIOR et al., 2014, p. 208).

$\mathrm{O}$ uso de recursos naturais e as questões ambientais decorrentes disso são temas recorrentes no cenário político, econômico e nas pesquisas acadêmicas (SÁ; OLIVEIRA; NOVAES, 2015, p. 61), sendo necessário repensar 0 uso das fontes de energia atuais e conscientizar a sociedade para o desenvolvimento sustentável, fomentando a Educação Ambiental para o uso de fontes alternativas de energia, a fim de garantir uma produção contínua, limpa e sem riscos de colapso (PAULINO et al., 2017, p. 140).

A Educação Ambiental constitui um processo de permanente aprendizagem que busca desenvolver instrumentos pedagógicos efetivos para criar e aplicar formas sustentáveis de interação entre o homem e o meio ambiente (SÁ; OLIVEIRA; NOVAES, 2015, p. 61). Ela implica em educação para a conservação, para o consumo responsável e para a solidariedade na repartição equitativa dentro de cada sociedade, entre as sociedades atuais e, entre estas e as futuras. Trata-se da gestão de sistemas de produção e de utilização dos recursos comuns, tanto quanto sistemas de tratamento de resíduos e sobra, integrando uma verdadeira educação econômica (SAUVÉ, 2005, p. 317).

A utilização da energia luminosa do sol é uma das opções mais promissoras para integrar a matriz energética brasileira, que apesar do seu potencial, fornece atualmente menos de $1 \%$ da energia elétrica gerada anualmente no Brasil. A alta incidência de radiação solar ao longo do ano no país, em especial na região nordeste, se deve à sua localização na região intertropical do planeta onde esse recurso energético é abundante. De acordo com o Atlas de Energia Solar (TIBA et al., 2000, p.19), o Nordeste possui irradiação solar similar às regiões do mundo com maior potencial, como a cidade de Dongoda, no deserto do Sudão, e a região de Dagget, no Deserto de Mojave, Califórnia (SOUSA, 2014, p. 13). 
A utilização da tecnologia de conversão fotovoltaica, torna possível o aproveitamento da irradiação solar por meio de células e painéis fotovoltaicos que converte a luz em eletricidade. Esse método de produção de energia tem benefícios ambientais, com impacto quase nulo e sua principal fonte se caracteriza por ser infinita e inesgotável. A tecnologia está se tornando, progressivamente, mais competitiva, tanto porque seus custos estão decrescendo, quanto a avaliação dos valores das outras formas de geração está se tornando mais real, sendo considerados agora fatores que antes eram ignorados, como os impactos ambientais (SOUZA, 2014, p. 19). Os painéis fotovoltaicos podem ser instalados em qualquer ambiente, interligados à rede elétrica ou de forma isolada com o auxílio de baterias. Desse modo, alguns requisitos podem ser seguidos para que o potencial energético solar seja aproveitado ao máximo, sendo adotada uma orientação solar favorável para as superfícies dos painéis fotovoltaicos (MARINOSKI; SALAMONI; RÜTHER, 2004).

A discussão desse tema no ambiente escolar é um ponto chave para se formar cidadãos mais conscientes e conhecedores dos efeitos causados por fontes não renováveis de energia, pois é o lugar onde tem-se mais encontros com conhecimentos estruturados em vários meios sociais. (CARAMELLO; STRIEDER, 2012, p.103). Neste contexto, a física articulada à Educação Ambiental pelo tema energia solar, pretende fomentar na educação básica o desenvolvimento da cidadania consciente, onde os conteúdos podem contribuir para desenvolver uma leitura crítica de mundo e possibilitar interferências na construção de uma sociedade mais equilibrada (PAULINO et al., 2017, p.140; SILVEIRA; GROENWALD, 2005, p. 115)

Os parâmetros curriculares nacionais trazem orientações para que sejam dadas novas dimensões ao ensino de física, promovendo contextualização do conhecimento integrado à vida dos alunos. Explorar os conteúdos de física para explicar gastos da conta de luz ou o consumo diário de combustível, como também temas relativos ao uso das diferentes fontes de energia em escala social, com seus riscos e benefícios. Além disso, deve-se tratar das células fotoelétricas e das radiações presentes no cotidiano, como também dos princípios gerais que permitem generalizar todas essas compreensões. No qual tenha um significado para o aluno no momento da aprendizagem, e não posterior a ele (BRASIL, 2000).

Assim, o presente trabalho teve como objetivo apresentar um estudo sobre a localização do sistema fotovoltaico para ensaios experimentais do Laboratório de Física e Energias Renováveis da Universidade de Pernambuco Campus Petrolina, realizado por um grupo de alunos de graduação, abordando os conceitos de energia solar e sustentabilidade, fomentando a Educação Ambiental no ensino de física. 


\section{Material e Métodos}

O Laboratório de Física e Energias Renováveis da Universidade de Pernambuco Campus Petrolina, desenvolve atividades de ensino e extensão de física experimental e pesquisas em energias renováveis. Localizado no município de Petrolina - PE, está inserido na Região do Submédio São Francisco, com alto potencial para geração de energia fotovoltaica, despertando o interesse por pesquisas de utilização dessa fonte como complemento energético às fontes convencionais.

A metodologia deste trabalho inclui alguns estudos prévios para a localização de um sistema fotovoltaico, tais como: estudo do potencial solar no local; ângulo de incidência solar para orientação e inclinação dos painéis; estudo do sombreamento. Além disso, inclui também o caminho metodológico seguido, tratando o tema de energia renovável no ensino de forma interdisciplinar, podendo ser aplicado em outras situações de aprendizagem.

\section{Localização e Estudo do Potencial Solar local}

As coordenadas do Laboratório de Física e Energias Renováveis da UPE Campus Petrolina foram obtidas com o uso do Google Earth. O local préselecionado para instalação das placas fotovoltaicas foi a parede externa do laboratório (Figura 1).
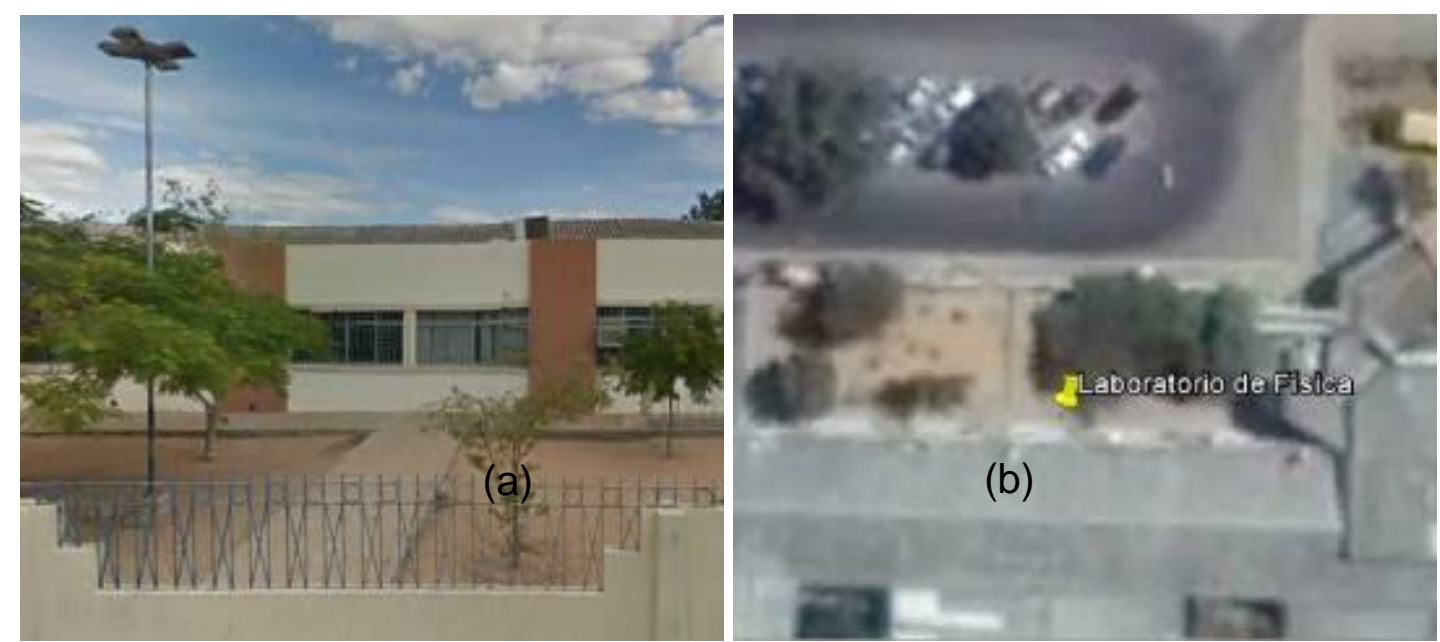

Figura 1: Local pré-selecionado para a instalação das placas solares: em (a) vista frontal e em (b) vista superior. Fonte: Google Earth adaptada pelos autores.

O estudo das relações geométricas entre os ângulos de incidência dos raios solares com a superfície terrestre da localidade, e também da placa solar, devem levar em conta a inclinação do Sol em relação ao plano da superfície e do local de instalação. Esses ângulos estão diretamente relacionados com a quantidade de raios solares incidentes nas placas, ou seja, são fatores que influenciam no desempenho delas. 
A partir das coordenadas geográficas, utilizou-se o banco de dados do Centro de Referência para Energia Solar e Eólica Sérgio Brito (CRESESB) para obtenção dos valores de irradiação solar para diferentes inclinações $\left(0^{\circ} \mathrm{N}, 8^{\circ} \mathrm{N}\right.$, $9^{\circ} \mathrm{N}, 14^{\circ} \mathrm{N}$ ), e definir a inclinação das placas fotovoltaicas que propicie maior rendimento energético.

\section{Análise da Geometria Sol-Terra}

A análise geometria Sol-Terra permite conhecer em quais aspectos o movimento anual da Terra em torno do Sol pode influenciar no desempenho do sistema fotovoltaico, acerca da variação da duração dos dias ao longo do ano para o município de Petrolina-PE.

Para maximizar a captação de energia ao longo do ano, deve-se considerar a orientação e a inclinação dos módulos fotovoltaicos. Em geral, os módulos devem ser orientados em direção à linha do equador. Para localizações no hemisfério Sul (Figura 2), as faces dos módulos devem estar orientadas em direção ao Norte Verdadeiro. Já para localizações no hemisfério Norte, devem estar orientados para o Sul Verdadeiro.

Na maioria dos locais, a direção do Norte ou Sul verdadeiro não coincide com o Norte ou Sul Magnético, então, são necessárias correções do referencial magnético que podem ser obtidas através de mapas e programas computacionais.

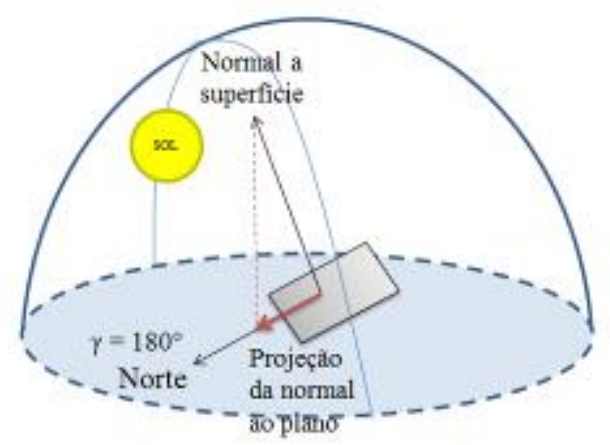

Figura 2: Orientação da face dos módulos fotovoltaicos para o norte verdadeiro em um dado local do hemisfério sul. Fonte: autoria própria.

Para que o sistema de energia solar fotovoltaica tenha o máximo de eficiência ao longo do ano, é necessário que os painéis sejam instalados com uma inclinação $(\beta)$ igual à latitude do local, podendo ter uma variação em torno de $10^{\circ}$ do ângulo dessa latitude (Figura 3). Caso o local esteja em uma latitude variando entre $-10^{\circ} \mathrm{a}+10^{\circ}$, é aconselhável uma inclinação mínima da $10^{\circ}$, para favorecer a autolimpeza das placas pela ação da água da chuva. 


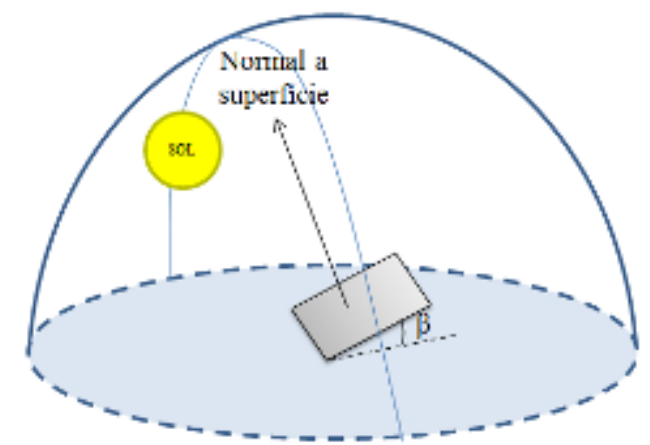

Figura 3: Ângulo de inclinação para os módulos fotovoltaicos.

Fonte: autoria própria.

\section{Estudo do Sombreamento}

Um aspecto importante a considerar durante o processo de instalação é a localização mais adequada para o gerador fotovoltaico. O local deve ter uma boa incidência de radiação solar, visto que o sombreamento provocado por prédios, árvores, postes, dentre outros objetos de entorno, pode reduzir significativamente o potencial de geração do sistema.

Para avaliação das possibilidades de sombreamento no local da instalação das placas foram medidos os parâmetros altura $(\mathrm{m})$ dos obstáculos, como postes e árvores, e a distância $(\mathrm{m})$ destes em relação ao local de instalação, a fim de verificar uma possível diminuição no desempenho dos conversores de energia, causada por esses obstáculos

A distância mínima destes obstáculos para instalação das placas solares foi avaliada utilizando um método matemático, baseado no fator de espaçamento (Equação 1) e a sua relação com a latitude (Figura 4) (PINHO et at., 2008; p.225).

$$
\mathrm{d}=\mathrm{F}_{\mathrm{c}}\left(\mathrm{h}_{\omega}-\mathrm{h}_{i}\right)
$$

Onde:

$\mathrm{d}$ = distância mínima entre obstáculo e sistema fotovoltaico $(\mathrm{m})$;

$\mathrm{Fe}=$ Fator de espaçamento de determinada latitude (ver figura 3);

hob = altura do obstáculo $(\mathrm{m})$

hi = altura de instalação do sistema. 


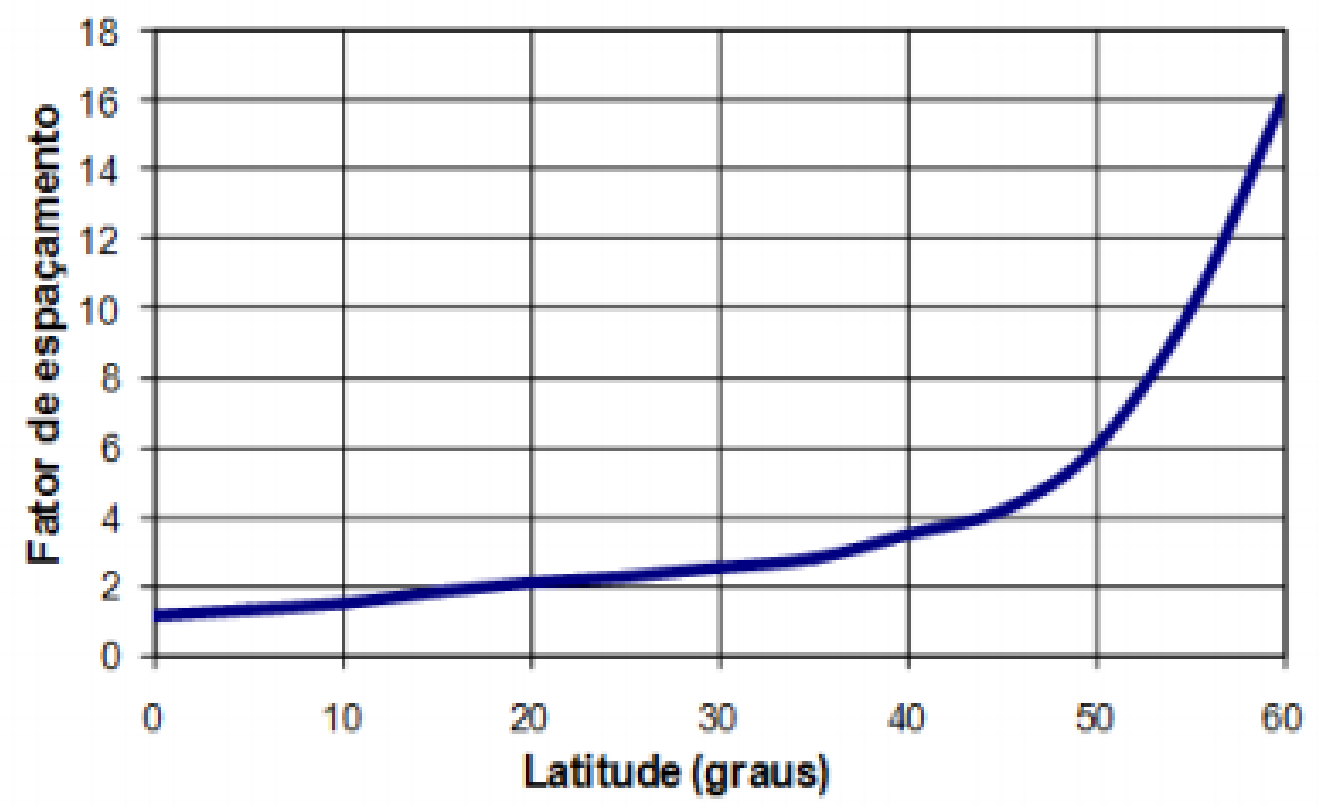

Figura 4: Fatores de espaçamento de acordo com cada latitude.

Fonte: PINHO, GALDINO, 2014.

\section{Uso de conceitos de energia solar na Educação Ambiental}

A abordagem do tema energia solar pode ser feita de forma interdisciplinar, pela inclusão de conceitos de geografia sobra a geometria SolTerra, da modelagem matemática pelo uso de equações e ferramentas de medida e também pela utilização de ferramentas tecnológicas como o Google Earth. Além disso, contribui para a discussão da temática do uso das energias renováveis e seus benefícios em relação aos combustíveis fósseis.

\section{Resultados e discussão}

As coordenadas do Laboratório de Física e Energias Renováveis da UPE Campus Petrolina obtidas com o uso do Google Earth $\circledast$ têm valores de longitude $40^{\circ} 28^{\prime} 44.3^{\prime \prime} \mathrm{W}$ e latitude $9^{\circ} 23^{\prime} 49.6^{\prime \prime} \mathrm{S}$. Como o município está localizado no hemisfério Sul, as placas fotovoltaicas devem ser orientadas em direção ao norte verdadeiro.

Os resultados obtidos do banco de dados do CRESESB, para obtenção dos valores de irradiação solar para diferentes inclinações é ilustrado pelo gráfico da Figura 5, que relaciona a irradiação solar diária média mensal (kWh.m${ }^{2}$. $\mathrm{dia}^{-1}$ ) com as inclinações. O estudo do potencial solar indica que os valores médios de irradiação solar para diferentes inclinações $0^{\circ} \mathrm{N}, 8^{\circ} \mathrm{N}, 9^{\circ} \mathrm{N}$ e $14^{\circ} \mathrm{N}$ são, respectivamente, 5,37, 5,41, 5,41 e 5,39 kWh.m ${ }^{-2} \cdot$ dia $^{-1}$, indicando uma melhor produção de energia para os ângulos $8^{\circ} \mathrm{N}$ e $9^{\circ} \mathrm{N}$. Entretanto, para 
latitudes entre $-10^{\circ} \mathrm{e}+10^{\circ}$, é aconselhável uma inclinação mínima de $10^{\circ}$, para favorecer a limpeza dos painéis fotovoltaicos.

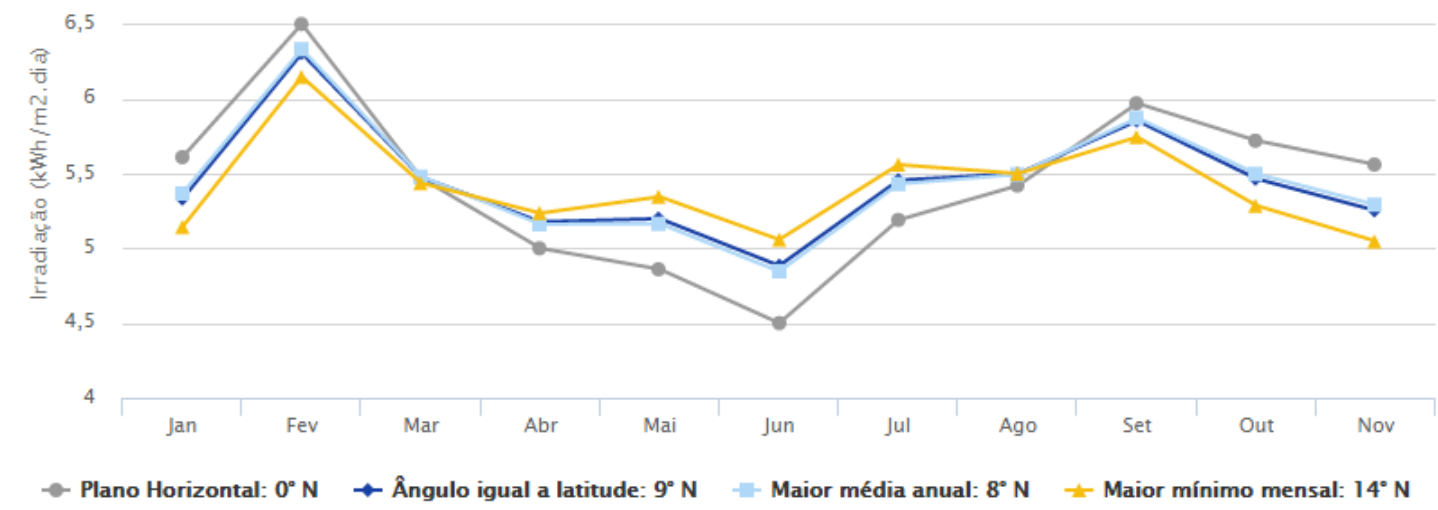

Figura 5: Gráfico de irradiação através dos meses do ano.

Fonte: CRESESB.

O local escolhido para a instalação das placas apresenta dimensões propicias para instalação (Figura 6).

As possíveis fontes de sombreamento observados no local são duas árvores e um poste de luz, cujas medidas se encontram na figura 7 .

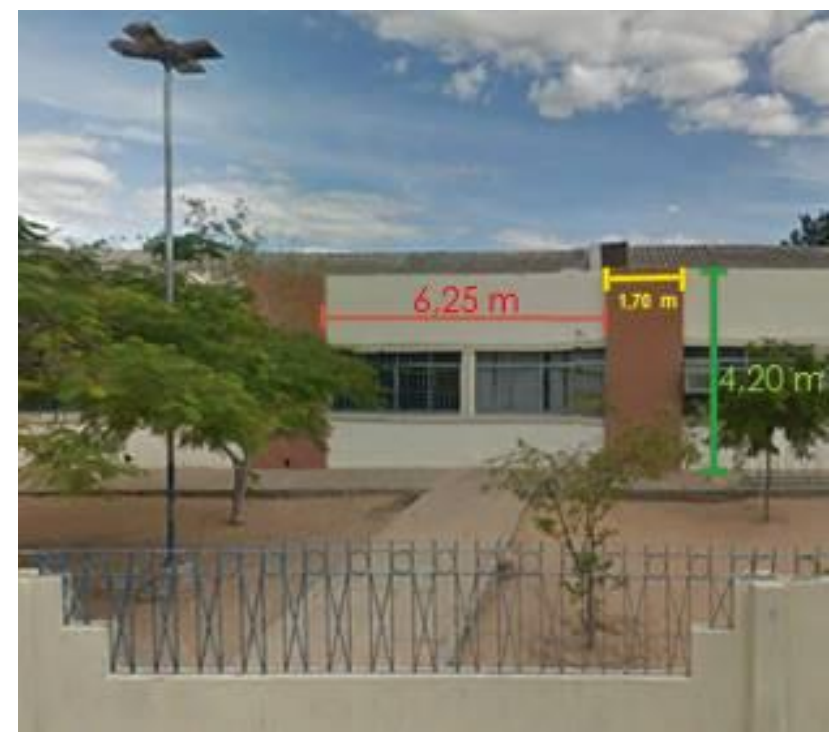

Figura 6: Medidas do local a se instalar as placas.

Fonte: autoria própria. 


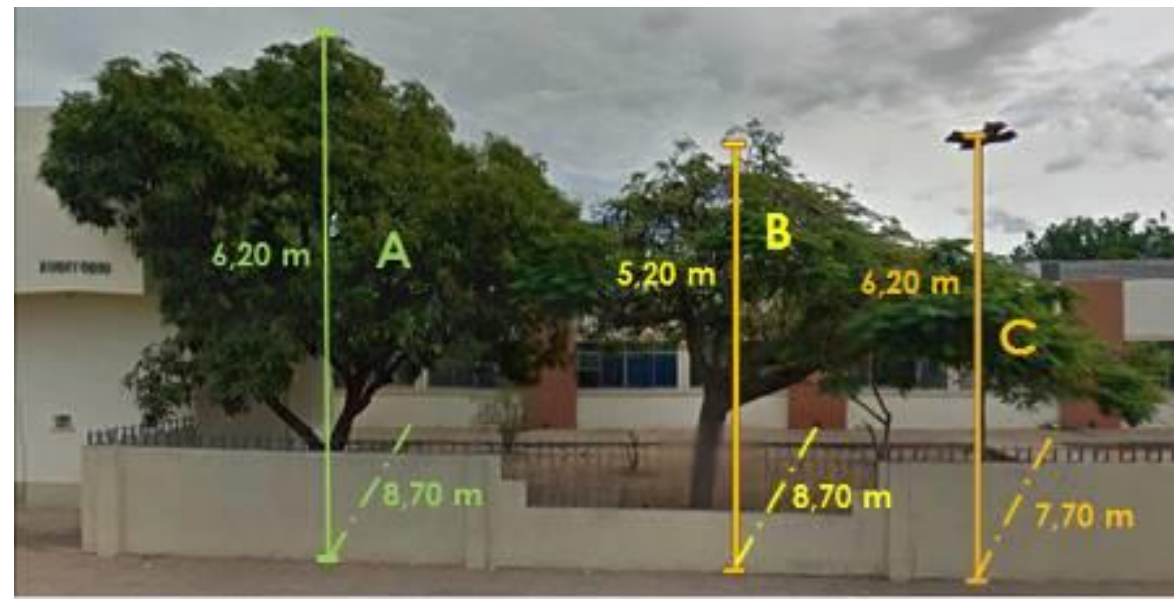

Figura 7: Alturas dos obstáculos e distâncias dos mesmos a parede de instalação das placas.

Fonte: autoria própria.

Considerando o limite do fator de espaçamento para a latitude do local igual a 2, aplicou-se os dados obtidos na equação do método para determinar a distância mínima que o sistema fotovoltaico deve ser instalado dos possíveis obstáculos de sombreamento. Como a distância mínima depende somente das alturas dos obstáculos e de onde será o sistema:

- Para os obstáculos A e C temos que:

$$
\begin{gathered}
\mathrm{d}=\mathrm{F}_{\mathrm{c}}\left(\mathrm{H}_{\mathrm{ob}}-\mathrm{H}_{\mathrm{i}}\right) \\
\mathrm{d}=2(6,2-4,2) \\
\mathrm{d}=4 \mathrm{~m}
\end{gathered}
$$

- Para o obstáculo B:

$$
\begin{aligned}
\mathrm{d}= & \mathrm{F}_{\mathrm{c}}\left(\mathrm{H}_{\mathrm{ob}}-\mathrm{H}_{\mathrm{i}}\right) \\
\mathrm{d}= & 2(5,2-4,2) \\
& \mathrm{d}=2 \mathrm{~m}
\end{aligned}
$$

As distâncias $A$ e $B$ são iguais a $8,7 \mathrm{~m}$ e a distância $C$ é $7,7 \mathrm{~m}$, sendo maiores que a distância mínima necessária calculada, indicando que esses obstáculos não causarão redução na produção de energia. 


\section{Uso de conceitos de energia solar na Educação Ambiental}

A introdução da temática de energia solar, como forma de promover Educação Ambiental, deve orientar o uso de recursos naturais para promover práticas sustentáveis por meio de reflexões, discussões e experiências, objetivando o desenvolvimento de habilidades e modificando atitudes em relação ao meio ambiente. Dessa forma, propõe-se inicialmente uma discussão sobre as fontes energéticas renováveis, pontuando suas contribuições e quais impactos podem causar ao meio ambiente. Esse debate em sala pode ser feito através de situações-problema, instigando nos alunos o pensamento crítico sobre o tema.

Como atividade sequencial, propõe-se fazer um estudo sobre a geometria Sol-Terra, integrando também conteúdos de geografia e reforçando a interdisciplinaridade, e em como os aspectos do movimento anual da Terra em torno do Sol pode influenciar no desempenho do sistema fotovoltaico, acerca da variação da duração dos dias ao longo do ano. Logo após, deve-se analisar as relações geométricas entre os ângulos de incidência dos raios solares com a superfície terrestre de localidade, considerando-se a orientação e a inclinação dos módulos fotovoltaicos para maior maximização da energia fotovoltaica. Para se obter as coordenadas do local escolhido para instalação, pode-se utilizar o Google Earth, e com isso favorecer a inclusão de recursos tecnológicos no ensino. Após a obtenção dos dados de latitude e longitude, utiliza-se o banco de dados do Centro de Referência para Energia Solar e Eólica Sérgio Brito (CRESESB) obtendo-se a média de irradiação solar mensal em diferentes inclinações $\left(\mathrm{kWh} \cdot \mathrm{m}^{-2} \cdot \mathrm{dia}^{-1}\right)$ para o local do país onde o estudo está sendo desenvolvido.

Adicionalmente, deve-se solicitar aos alunos que analisem a sua conta de energia residencial, verificando o gasto mensal. Feito isso, deve-se realizar uma comparação para verificar a economia anual, com a instalação de módulos fotovoltaicos interligado ao sistema elétrico da casa, calculando o valor cedido a rede elétrica, e o tempo de amortização dos custos de implantação do sistema, verificando os benefícios financeiros e ambientais.

\section{Considerações Finais}

O estudo do tema de energia pode ser explorado de forma a promover a Educação Ambiental e a interdisciplinaridade, pela abordagem relacionada às fontes renováveis de energia na promoção do desenvolvimento sustentável.

O uso de estudos de caso na abordagem do tema contribui para que os alunos vivenciem de forma mais concreta as questões sobre energias renováveis e sua importância econômica e ambiental.

Adicionalmente, conscientiza sobre os benefícios do uso de fontes renováveis de energia para o meio ambiente, abordando a Educação Ambiental de forma transversal e interdisciplinar no ensino médio, tal como preconizado nos parâmetros curriculares nacionais, e fortalecendo a formação de professores de física. 


\section{Agradecimentos}

À Fundação de Amparo à Ciência e Tecnologia de Pernambuco (FACEPE), pelo apoio financeiro à pesquisa.

À Coordenação de Aperfeiçoamento de Pessoal de Nível Superior Brasil (CAPES) - Código de Financiamento 001.

\section{Referências}

BRASIL. Ministério da Educação. Parâmetros Curriculares Nacionais para o Ensino Médio. Brasília: ME, 2000.

BRASIL. Ministério de Minas e Energia. Empresa de Pesquisa Energética. Demanda de energia 2050. Rio de Janeiro: EPE, 2014.

CARAMELLO, G.W.; STRIEDER, R.B. Elementos para inserir as questões ambientais em aulas de física: da prática baseada em temas à complexificação do conhecimento. Pesquisa em Educação Ambiental, São Paulo, v. 6, n. 2, p. $101-117$, jul. 2012.

CRESESB. Base de dados de radiação solar incidente. Disponível em: http://www.cresesb.cepel.br/index.php?section=sundata. Acesso em: 27 set. 2016.

EIFLER NETO, E.E. Estudo da complementariedade entre disponibilidades de energia hídrica e eólica na região nordeste do Brasil. Monografia. 2012. 92 f. Bacharelado em Engenharia Ambiental. Instituto de Pesquisas Hidráulicas e Escola de Engenharia, Universidade do Rio Grande do Sul, Porto Alegre.

LIMA JUNIOR, C.; SAMPAIO, E.V.S.B.; LIMA, R.L.F.A.; MENEZES, R.S.C. Potencial de Aproveitamento Energético de Fontes de Biomassa no Nordeste do Brasil. Revista Brasileira de Geografia Física. Recife, v. 07, n. 02, p. 207-221, 2014.

MARINOSKI, D.L.; SALAMONI, I.T.; RÜTHER, R. Pré-dimensionamento de um sistema solar fotovoltaico: estudo de caso do edifício sede do CREA-SC. Anais do I Conferência Latino-Americana de Construção Sustentável, 2004. Disponível em: http://www.labeee.ufsc.br/antigo/linhas pesquisa/ energia solar/publicacoes /pre dimensionamento.pdf. Acesso em: 03 out. 2016.

PAULINO, T.F.; PINTO, M.S.; COSTA, G.V.; BAMBIRRA, M.B.; PAULINO, E.S. Oficinas educacionais: atividade de extensão como método para a melhor utilização da energia para estudantes do ensino fundamental. Revista Brasileira de Educação Ambiental. São Paulo, v.11, n. 5, p. 139 - 151, 2017.

PINHO, J.T.; BARBOSA, C.F.O.; PEREIRA, E.J.S.; SOUZA, H.M.S.; BLASQUES, L.C.M.; GALHARDO, M.A.B.; MACÊDO, W.N. Sistemas híbridos: soluções energéticas para a Amazônia. Brasília, Brasil: Ministério de Minas e Energia, 2008. 396 p. 
SÁ, M.A.; OLIVEIRA, M.A.; NOVAES, A.S.R. A importância da Educação Ambiental para o ensino médio. Revista Brasileira de Educação Ambiental. São Paulo, v. 10, n. 3, p. 60-68, 2015.

SAUVÉ, L. Educação Ambiental: possibilidades e limitações. Educação e Pesquisa. São Paulo, v. 31, n. 2, p. 317-322, 2005.

SILVEIRA, R.B.; GROENWALD, C.L.O. Energia solar no ensino da matemática: uma proposta para o ensino médio. Acta Scientiae. Canoas, v. 7, n. 1, p. 111 122. 2005.

SOUSA, M.L.A. Uso de bombeamento fotovoltaico para irrigação de unidades de produção agrícola de pequeno porte. 2014. 78 f. Monografia (Bacharelado em Energia Elétrica) - Centro de Tecnologia, Departamento de Engenharia Elétrica, Graduação em Engenharia Elétrica, Universidade Federal do Ceará, Fortaleza.

TIBA, C.; FRAIDENRAICH, N.; LYRA, F.J.M.; NOGUEIRA, A.M.B.; GALLEGOS, H.G. Atlas solarimétrico do Brasil: banco de dados terrestres. Recife: Editora Universitária da UFPE, 2000. 